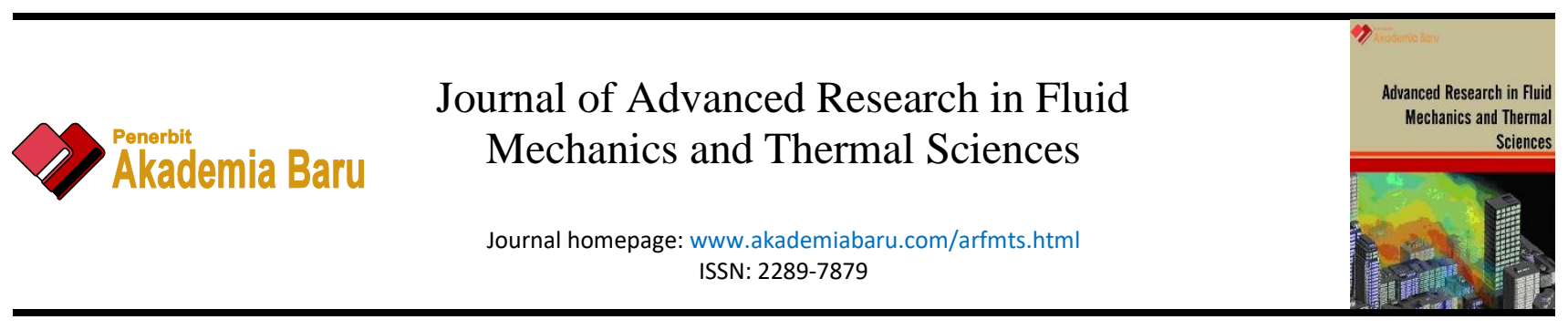

\title{
Design of a Centrifugal Compressor Test Rig
}

\author{
S. V. Ajaicimhan ${ }^{1}$, Natteri M Sudharsan ${ }^{1, *}$ \\ 1 Department of Mechanical Engineering, Rajalakshmi Engineering college, Chennai, India
}

ARTICLE INFO ABSTRACT

\section{Article history:}

Received 19 May 2020

Received in revised form 8 July 2020

Accepted 8 July 2020

Available online 18 December 2020

\begin{abstract}
Centrifugal compressors find their use in many areas especially in turbochargers which are used extensively in automobiles and in aircrafts and defence systems. This paper presents the design of a complete test facility for testing centrifugal compressors. It starts with design of a Combustor - the driving unit for the test facility. The Centrifugal compressor being tested is a part of a turbocharger. The combustor feeds the Turbine side of the test section with hot gases for running the compressor at desired speeds. This particular choice eliminates the need for the inclusion of heavy speed reducing gears when an electric motor is used as the driving unit. The designed combustor was numerically simulated and subsequently optimized for the given working conditions. The simulated results showed good agreement with the target criteria. Further, the choice and placement of the measuring instruments for the entire test rig and their permissible deviations are listed and finally the basic operating sequence for the entire rig is also drafted for in-house development of automation of the entire test rig thereby making it a complete guide for the setting up of such facility, hitherto establishing a complete guideline of all subsystems which will enable in building such similar facilities in varying magnitudes in the future.
\end{abstract}

Keywords:

Turbocharger; combustor; compressor test rig

Copyright $@ 2021$ PENERBIT AKADEMIA BARU - All rights reserved

\section{Introduction}

Performance testing is a very important step in the design and development of any product. Testing assumes even greater significance in the case of compressors where the developed component is to be tested to find the operating range and, in many cases, it is tested at specific conditions for its surge, range and speed. There have been several advances in the field of compressor testing around the world especially in the last couple of decades and some of them are discussed here to present an overall view of the prevailing testing facilities and the nature of tests that can be carried out. Fahad et al., [1] have discussed in detail about the procedure for setting up a Testing facility and about the selection of driver unit. Their work focuses to a large extent, on development of a code to assess the input power requirement, speed and required torque of a

\footnotetext{
* Corresponding author.

E-mail address: sudharsann@asme.org
}

https://doi.org/10.37934/arfmts.79.1.6380 
centrifugal compressor so that an appropriate driver can be chosen, which would eventually dictate the necessary instrumentation required for the test facility. Chernov [2] developed a Compressor test stand to study the overall performance at Lappeenranta University. The stand developed is a closed loop, electric motor driven unit with necessary pressure and temperature sensors. The rig was designed in accordance with ISO5389 - Turbo compressors standard. This new test stand is dedicated for centrifugal compressors with a flow rate of $1.8 \mathrm{Kg} / \mathrm{s}$ and a pressure ratio of 2.5 . The University of Aachen RWTH has two such test facilities built to test centrifugal compressors with both of them running on electric motors and pressure ratio reaching as high as 6:1 [3]. Meuleman et al., [4] of Eindhoven University have conducted studies especially for the measurement and modelling of Centrifugal compressor surge and concluded that the surge frequency increased as the throttle valve was closed, which indicated that the system experienced a classic or deep surge. Lim et al., [5] have developed a complete test rig to study compressor surge for a detailed understanding of the compressor as it goes to surge. Two frequencies related to surge were observed and it was concluded that surge was the reason for excitation in the pressure waves. Additionally, the effect of variation of impeller tip clearance on performance was studied and the influence of the same over surge control was observed. The test rig used an Induction motor as the driver and a pressure ratio of 1.7. Bontempo et al., [6] have developed a new generator to supply hot gases at a varied range. This system is safer to operate, primarily due to the rigidity of the diesel engine and flexible flow control of the turbine inlet. A supercharging station built externally, with latest engine control module allows for the flexibility in controlling the inlet side of the turbine. Vital parameters like flow rate and temperature can be controlled independently.

\section{Design Targets}

Having described some of the facilities around the world, the current work focuses on the design and development of a complete test facility for centrifugal compressor testing, as test facilities are scarce in Universities and moreover the testing is confined, to a large extent to Industries predominantly in the form of turbocharger facility. Globally, manufacturers of turbochargers will not be able to provide all the necessary information on the operating characteristics and performance of the turbocharger when integrated as a part of the prime mover. The requirement for testing the turbocharger for a wide ranges and types makes it expensive and prohibitive. Thus, it is necessary for the OEM's to develop customized gas stand to suit the operating conditions of the prime mover / engine. Moreover, standard testing with electrical drive may not be able to simulate the pulsatile nature of the exhaust gases through the turbine and hence requiring a specifically designed gas stand. A fully dedicated test facility can accelerate the research in this field which continues to evolve, till date. The existing facilities use electric motors as drivers for compressor testing, and in certain cases the driving unit is a gas turbine. The data acquisition has become completely automated, and are provided as commercial packages, having said that, the need for an in-built data acquisition system arises either due to cost constraint or due to the sensitive and confidential nature of the place of deployment. Providing a complete guideline to the setting up a test facility beginning from the choice of driver unit, instruments and their placements, and the operating sequence, can lead the development of an in-house facility especially in critical areas like defence and to academia in general, where overall cost becomes a major constraint. The current work aims to serve as a guide line for the complete development of the test rig starting from the selection of suitable driver unit till the procedure to operate the entire test rig. Such a facility will aid in understanding complex phenomena such as surge and stall, the frequencies of such stall can be measured with proper instrumentation and eventually will lead to an improved design in blade profile, and consequently an 
improved range of operation. The work also focuses on adhering to best practices like complying to globally accepted standards for the selection and placement of measuring instruments their permissible deviations for error free data acquisition. Van Laningham [7] in his paper, emphasized the use of suitable standards for the instrumentation of the test rig, it is hitherto being mentioned about the placements of all instruments. It is expected that, providing such a skeleton will lead to development of individual codes for automatic data calculation thereby eliminating the need for purchasing the commercially available packages particularly in cases where the institutes opt for inhouse development of the entire rig. Moreover, the rigs can be customized according to the nature of testing once the complete instrumentation is known. Some of the distinguishing features of the current test rig design are summarised as follows

i. It can generate both hot air and cold air flow tests which means that the turbine side can be run with only pressurized air and the mapping can be done and when the combustion is preferred, the combustor can be switched on and a hot air flow can be run for real time mapping for the turbine and the compressor for the entire range.

ii. Compressor stability estimation can be carried out.

iii. The dynamic characteristics of the rotors (i.e.) diffuser and the impellers can be studied under real time load fluctuations on the turbine side.

iv. This test rig can also be used to evaluate the performance of a turbocharger as the turbocharger also takes in the hot gases from the combustor on the turbine side.

v. Turbine mapping is also possible (hot flow mapping) if the compressor specifications are fixed. A suitable turbine can be designed and tested by using this combustor driven test rig in order to match it with an existing compressor.

\section{Selection and Design Methodology of Test Rig}

A typical Compressor test rig consists of the following subsystems

i. Compressor and Storage vessel - for air delivery to combustor

ii. Combustor - to produce the flue gases which moves the turbine side.

iii. Piping and Instrumentation - which provides us with the data for computation

iv. DAQ - data acquisition system for proper collection of data.

There have been several instances where a compressor testing facility was run with a gas turbine engine. Turner [8] proposed a compressor test facility which uses a Rolls-Royce turboprop engine as driver. A combustor driven test facility is chosen over an Electric driver considering the huge power demand of the driving motor, plus the associated step-down gearbox facility which needs to be custom made for the range of compressors that are likely to be tested in this facility. The above factors amount to huge investment financially which increases the total cost of the entire rig. Also the necessity for a robust Speed control in the motor side also adds additional cost [9]. The abovementioned disadvantages can be minimized when a combustor is designed specifically to a limited mass flow rate variance instead of an equivalent motor. A storage vessel and its associated compressor are sufficient to drive the test component. The proposed test rig is open loop in nature, meaning, the compressed air from the "Test Compressor" is left to ambient which also reduces the complexity of the rig and the cost involved the associated instrumentation for feedback are also cut down. The current work focuses on designing the entire test rig as mentioned above from the storage vessel to the data acquisition (DAQ) system. 


\subsection{Storage Vessel}

Storage vessel, as the name suggests, are used to store fluids under a specified condition and then released as and when it is required during an experiment/ operation. The storage vessel plays a crucial role in the continuous operation the turbocharger test rig. The turbine requires a continuous supply of flue gases at $1 \mathrm{Kg} / \mathrm{s}$ in order to test the component for its operating range. The entire design of the storage vessel for the current project was calculated according to ASME Boiler and Pressure Vessel Code Sec. VIII Division I [10] and two suitable high mass flow rate compressors delivering around $0.5 \mathrm{Kg} / \mathrm{s}$ were identified for feeding the storage vessel with pressurized air. As the design of the pressure vessel is a generic work, it has not been discussed further.

\subsection{Combustor}

Combustor is the component in which the compressed air from Compressor / storage vessel gets mixed with the fuel and combustion takes place. The hot gases then go to Turbine for expansion and produce power. Design of a combustor involves the consideration of many parameters like Air Partitioning between the various zones (Primary zone, Secondary zone, dilution zone) The Air fuel ratio - which directly controls the Entry temperature of the hot gases that strike the Turbine blades and design of the Diffuser plays an important role in avoiding stall. The combustor design consists of the following subcomponents
i. Diffuser
ii. Primary zone
iii. Secondary zone
iv. Dilution zone

The development of combustor dates back to as early as 1950's and continues till date. Koupper et al., [11] the varied demands being the prime reason for such continuous developments. With the evolution of Axial turbines and compressors, the development in combustor saw a shift from Tubular type [12] to Can - annular (Tubo-annular) types [11,13]. As the combustor's design is influenced by numerous parameters ranging from swirler dimensions[11], effusion cooling holes \& their inclinations and the main flow direction [14], the need for optimization increases according to the application. The influence of parameters on the main design were initially determined only by experimental studies. However, with the development of numerical simulation and computational sources, the studies have shifted from mere flow visualization studies [15] to optimization [11].

The current work focuses on the design and optimization of tubular combustor for a Centrifugal compressor test rig. The role of CFD in optimizing the combustor has assumed greater significance as it helps in avoiding phenomena like hot streaks during combustor - turbine interface. The flow at the exit of a combustor is usually highly unsteady in nature due to the presence of flue gases at high temperature, as the fuel mass flow rate is increased. The hot gases on interaction with air in dilution zone gives rise to turbulent, non-uniform mixture. This non-uniformity can cause vital changes within the turbine. These interactions can cause serious damage to the blade material which results in a drop in efficiency and changes in heat transfer $[16,17]$. It seen from experimental studies that if the hot streak is non-uniform in nature, a large change in heat transfer co-efficient is seen and also leads to accumulation of gases at end walls, which implies that the turbine stage efficiency is directly influenced by the non-uniformity of the temperature at the combustor exit. The current paper focuses on the numerical simulation of the developed combustor in order to check the above phenomena which proves as a vital optimization. Advancement in numerical simulations and 
computational resources have led to exponential growth in visualizing the flow in combustors especially during the last two decades. As early as in 1992, Smith et al., [15] have been able to successfully validate a 3D combustor and optimize NOx emissions virtually. Shang et al., [18] were able to successfully validate the experimental findings with CFD code on the non-uniformity of temperature at combustor exit. Shih et al., [19] came up with a modified K- $\varepsilon$ Eddy viscosity model for High Reynolds number flow. Schronfeld and Rudgyard [20] developed an Hybrid solver exclusively for aero components named ABVP. Simmone et al., [17] conducted extensive CFD simulation to investigate the effects of Non-uniform temperature profile in a turbine blades with much higher accuracy (0.8\% deviation). Finally, Koupper et al., [11] were successfully able to optimize the annular combustor for a high pressure turbine with as many as 38 million cells for a sector of the Combustor. Also the Turbulence handling has evolved from a simple closure for RANS equation in [14] to highly complicated and time consuming LES as found in the works of Koupper et al., [11] with a time step of 0.24 micro seconds.

Designing a combustor which can deliver hot gases at $1 \mathrm{~kg} / \mathrm{s}$ at $900 \mathrm{~K}$ was the main criteria for this test facility. The design of all the subcomponents were carried out using empirical relations [21-23] as shown below. The main casing area is obtained by two empirical approaches viz by aerodynamics and by combustor efficiency and are represented by Eq. (1) and (2) respectively.

By Aerodynamics

$\mathrm{CC}_{\mathrm{A}_{\mathrm{ref}}}=\left[\frac{\mathrm{R}}{2}\left(\frac{\mathrm{CC}_{\mathrm{m}_{3}} \sqrt{\mathrm{CC}_{\mathrm{T}_{3}}}}{\mathrm{CC}_{\mathrm{P}_{3}}}\right)^{2}\left(\frac{\Delta \mathrm{P}_{3 \rightarrow 4} / \mathrm{q}_{\mathrm{ref}}}{\Delta \mathrm{P}_{3 \rightarrow 4} / \mathrm{P}_{3}}\right)\right]^{0.5}$

By Combustor Efficiency

$\theta=\frac{\mathrm{CC}_{\mathrm{P}_{3}}^{1.75} \mathrm{CC}_{\mathrm{A}_{\mathrm{ref}}} \mathrm{CC}_{\mathrm{D}_{\mathrm{ref}}{ }^{\wedge} 0.75 \mathrm{e}^{\mathrm{CC} \mathrm{T} 3 / \mathrm{b}}}}{\mathrm{CC}_{\mathrm{m}_{3}}}$

After obtaining the main casing area dimensions, the other parameters like swirler diameter, primary secondary and dilution zones dimensions were calculated using the following relations.

Swirler Equation: $\mathrm{CC}_{\dot{\mathrm{m}}_{\mathrm{Sw}}}=\left\{\frac{2 \mathrm{CC}_{\rho_{3}} \Delta \mathrm{CC}_{\mathrm{P}_{\mathrm{Sw}}}}{\mathrm{CC}_{\mathrm{K}_{\mathrm{Sw}}}\left[\left(\sec \theta / \mathrm{CC}_{\mathrm{A}_{\mathrm{Sw}}}\right)^{2}-1 / \mathrm{CC}_{\mathrm{A}_{\mathrm{L}}}^{2}\right]}\right\}^{0.5}$

Swirler Number $\mathrm{S}_{\mathrm{N}}=(2 / 3)\left[\frac{1-\left(\mathrm{D}_{\mathrm{hub}} / \mathrm{D}_{\mathrm{sw}}\right)^{3}}{1-\left(\mathrm{D}_{\mathrm{hub}} / \mathrm{D}_{\mathrm{sw}}\right)^{2}}\right] \tan \theta$

Liner Diameter: CCaopt $=1-\left(\frac{\mathrm{m}_{\mathrm{A}}}{\mathrm{m}_{\mathrm{r}}}\right)^{\frac{2}{3}}\left(\frac{\Delta \mathrm{P}}{\mathrm{q}_{\mathrm{ref}}}\right)^{\frac{-1}{3}}$

Primary Zone Pressure Loss

$$
\left(\frac{\Delta \mathrm{P}}{\mathrm{q}_{\mathrm{ref}}}\right)_{\min }=\left(\frac{\mathrm{m}_{\mathrm{Pz}}}{\mathrm{m}_{\mathrm{r}}}\right)^{2}\left(\frac{\mathrm{A}_{\mathrm{r}}}{\mathrm{A}_{\mathrm{L}}}\right)^{2} \tau_{\mathrm{pz}\left(2 \tau_{\mathrm{pz}}-1\right)}
$$


Secondary zone Equations for diameter of the holes and no. of holes are obtained from Eq. (7) through (9)

$$
\begin{aligned}
& \frac{Y_{\max }}{d_{j}}=1.15 \sqrt{\frac{q_{j}}{q_{r}} \frac{q_{r}}{q_{L}}\left(1-\frac{q_{A}}{q_{r}} \frac{q_{r}}{q_{j}}\right)} \\
& d_{h}=\frac{d_{j}}{\sqrt{C_{D}} \sin \theta} \\
& N_{h S Z}=\frac{4 m_{s z}}{\rho_{r} \pi d_{j}^{2} V_{j}}
\end{aligned}
$$

Dilution zone equation

$$
\frac{Y_{\max }}{d_{j}}=1.15 \sqrt{\frac{q_{j}}{q_{r}} \frac{q_{r}}{q_{L}}\left(1-\frac{q_{A}}{q_{r}} \frac{q_{r}}{q_{j}}\right)}
$$

\subsection{Numerical Schemes}

The choice of cells for the domain were of polyhedral type and the overall cell count was kept at around $2 * 10^{6}$ Cells. Considering the flow to be high Reynolds number flow $\left(\sim 1.12^{*} 10^{6}\right)$ and as the holes are in the order of $10^{-3} \mathrm{~m}$, it was necessary to capture the effect near the wall as those were the main contributions to jet penetration and temperature distribution. Therefore, the wall $y+$ was kept around 15 for all further iterations and the results were documented. To handle combustion, a nonadiabatic Presumed Probability Density Function (PPDF) model was used. In this model, mean mixture fraction and enthalpy was estimated on the grid, while the other parameters like temperature and density were obtained as functions of the mean parametric variables, after an averaging process around a presumed probability distribution that is considered to represent turbulent fluctuations. The main improvement of using non- adiabatic model over an adiabatic model is the presence of a heat loss ratio factor $(\gamma)$. In an adiabatic PPDF model the value of a scalar (say temperature and density) is a function of molecular concentration and the initial temperature at that location, whereas, in non - adiabatic PPDF model the heat loss ratio is considered and the enthalpy is tracked on the grid to provide a more accurate representation of the scalar at that particular point. The heat loss ratio is given by the following equation (Star CCM+ [24])

$\gamma=\frac{h_{a d}(f)-h}{h_{\text {sens }}(f)}$

where $h_{a d}$ - adiabatic enthalpy, $h$ - cell enthalpy, $h_{\text {sens }}$ - sensible enthalpy and $f$ - mixture fraction.

Another important parameter is the SPECIFIC HEAT of the fuel used. The specific heat values for the fuel $(\mathrm{C} 12 \mathrm{H} 23$ and $\mathrm{C} 3 \mathrm{H} 8)$ both were collected for temperatures ranging from $300 \mathrm{~K}$ to $1500 \mathrm{~K}$ and then the values were plotted to get a function for the specific heats of both the fuels. The functions obtained were

for $\mathrm{C} 3 \mathrm{H} 8$ (Propane): $\mathrm{c}_{\mathrm{p}}=\mathrm{AT}^{4}+\mathrm{BT}^{3}+\mathrm{CT}^{2}+\mathrm{DT}+\mathrm{E}$

for $\mathrm{C} 12 \mathrm{H} 23$ (Jet fuel): $\mathrm{C}_{\mathrm{p}}=\mathrm{AT}^{6}+\mathrm{BT}^{5}+\mathrm{CT}^{4}+\mathrm{DT}^{3}+\mathrm{ET}^{2}+\mathrm{FT}+\mathrm{G}$ 


\subsection{Optimization}

As the combustor needs to be designed afresh, it gives a good scope for optimization as there are so many parameters that can be varied. However, the overall design requirement restricts certain key parameters like casing diameter, diffuser inlet diameter (this has to be in tandem with the primary air supply line) and the exit pipe diameter has to be in tandem with the test components' dimension. The vital parameters like choice of diffuser and the secondary and tertiary zone diameter holes and their arrangement can be varied, along with their arrangement in order to achieve good penetration of thereby reducing the exit temperature profile. The following table (Table 1) lists out the possible parameters that can be varied and the ones that were varied for the current design and analysis in order to achieve the defined target.

Table 1

List of parameters varied in combustor design

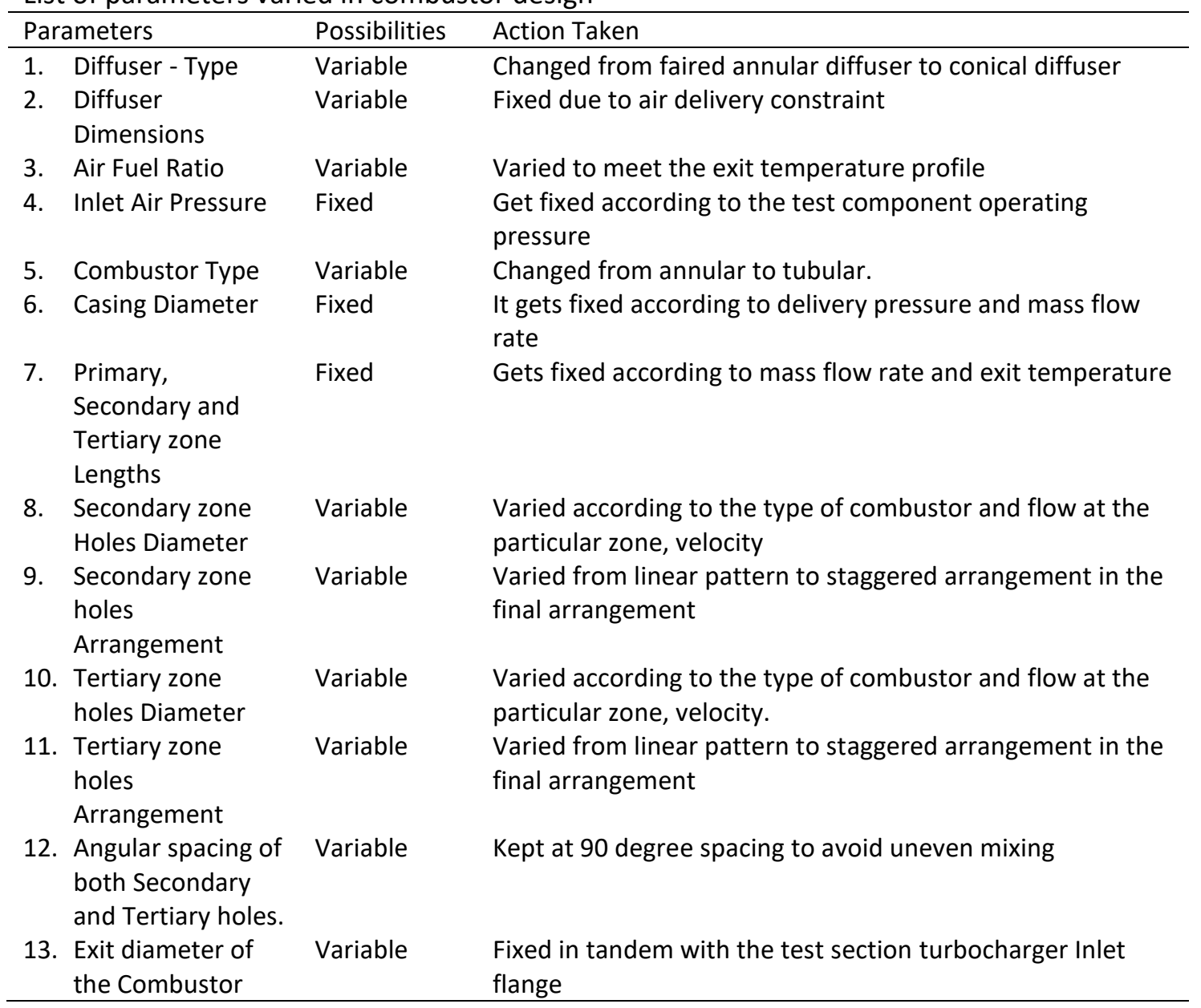

\section{Results and Discussions}

Having described the design methodology and the numerical set up in previous sections, the current section focuses on the results of the numerical simulations. An initial design as presented in Figure 1(a) was carried out using a faired diffuser and the simulations performed using Jet fuel are discussed here. From the results, it was observed that there is a poor penetration of secondary and tertiary air into the main stream as can be seen in Figure 2(a) and as a result of poor penetration, there is a large temperature gradient across the width of the combustor as shown in Figure 3(a). This 
temperature instability gives rise to thermal stress for the combustor. In order to tackle the above unfavourable condition, a new model was proposed and presented in Figure 1(b), where the faired diffuser was replaced by a normal diffuser.

The usage of normal diffuser implies that the inlet air has to be split into 3 components and introduced accordingly i.e. the primary, secondary and tertiary air will not enter the combustor at the same time like the previous case (Figure 1(a)) and the overall type of the combustor has been changed from tubo-annular to tubular combustor. The new model necessitates the use of additional control components as shown in Figure 1(b). Although there is an increase in the number of components, the results are in good agreement with the target criteria as can be seen from the Figure 2 (b) and 3 (b) respectively. One can observe that there is a good penetration of the secondary and tertiary jets into the main stream and the temperature instability has been totally removed whilst maintaining the target (surface average of 900K).
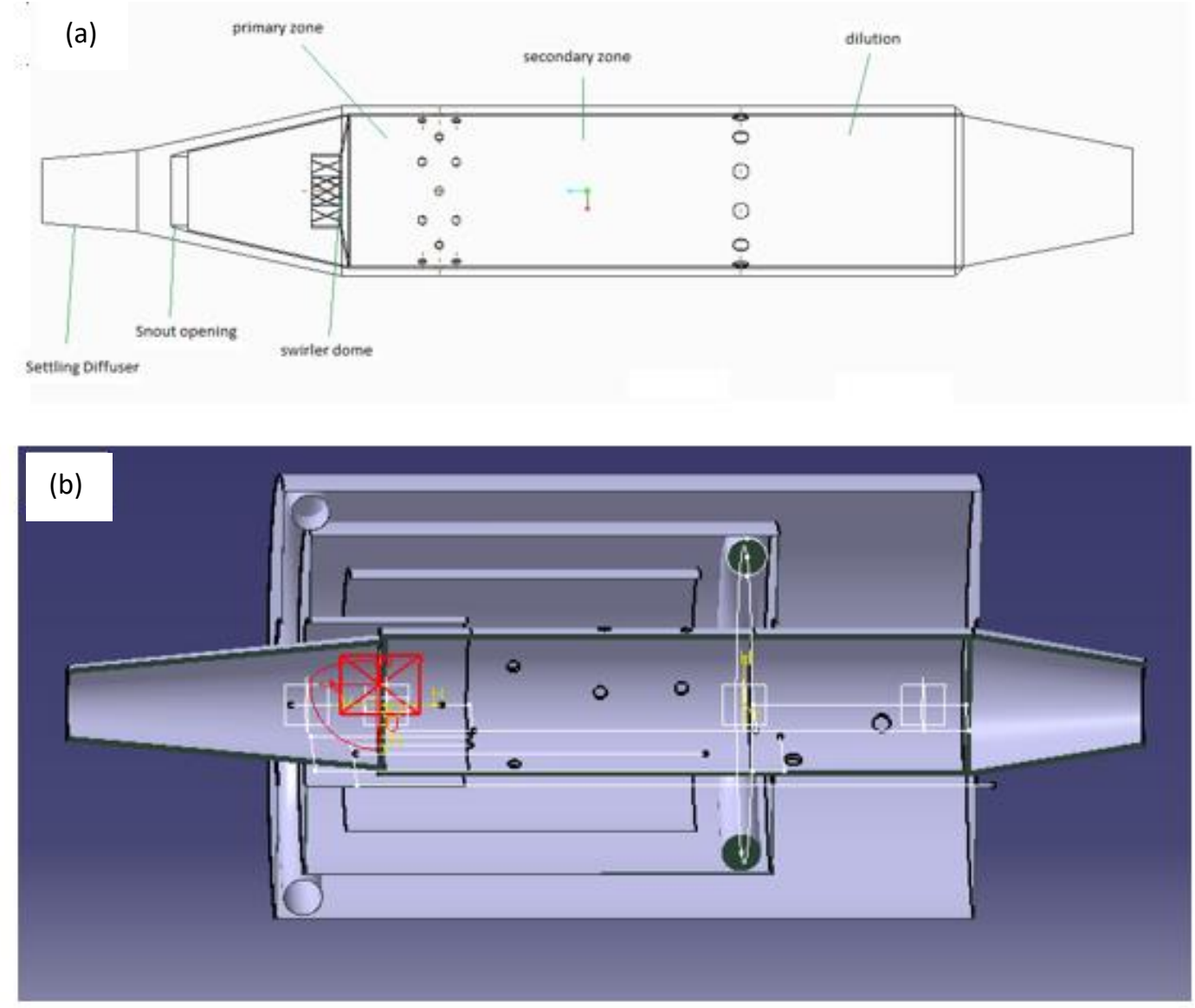

Fig. 1. (a) Combustor design initial, (b) final design with controls for secondary and dilution zones 


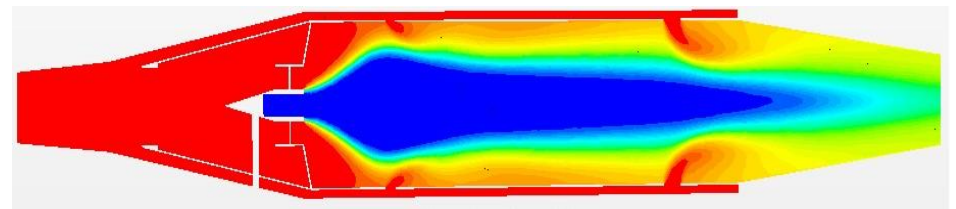

(a)

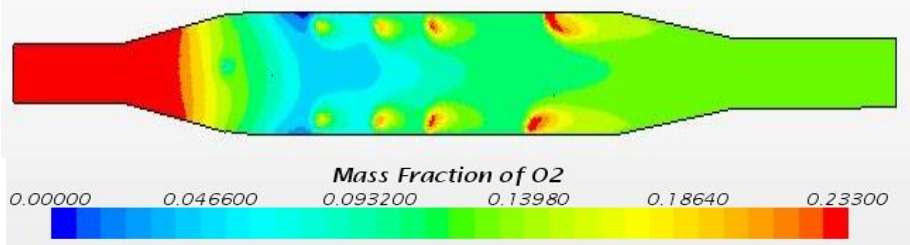

(b)

Fig. 2. Mass fraction of Oxygen- penetration of air into the main stream in (a) old and (b) new design

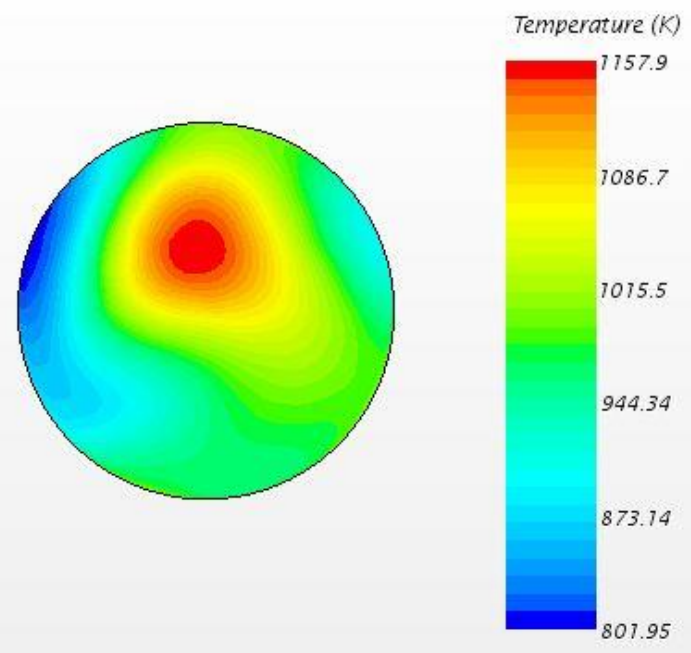

(a)

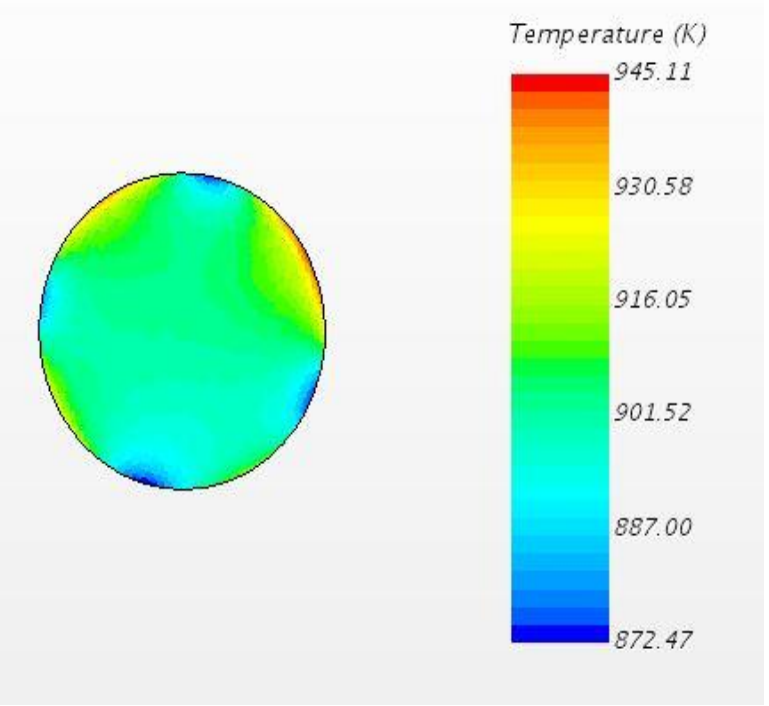

(b)

Fig. 3. Temperature plots at the exit of the combustor (a) old and (b) new design 
Thus, to conclude, it has been evident from the above results that the new design was successfully able to overcome the temperature instability and the poor penetration effects and maintain the target exit temperature profile whilst undergoing a small change in the overall dimensions, the major changes being made to secondary and tertiary zone holes as listed in the Table 2 to Table 6 below. The above listed phenomena could be identified only via a proper CFD simulation thus implying the importance of numerical techniques in optimizing a given component.

Table 2

Combustor dimensions

\begin{tabular}{|c|c|c|c|c|c|c|}
\hline Iteration & $\begin{array}{l}\text { Mass } \\
\mathrm{CC}_{\mathrm{m} .3}(\mathrm{Kg} / \mathrm{s})\end{array}$ & $\begin{array}{l}\text { Pressure } \\
\mathrm{CC}_{\mathrm{P} 3} \text { (bar) }\end{array}$ & $\begin{array}{l}\text { Temperature } \\
\mathrm{CC}_{\mathrm{T} 3}(\mathrm{~K})\end{array}$ & Approach & Diameter(m) & $\begin{array}{l}\text { Final } \\
\text { Diameter(m) }\end{array}$ \\
\hline Initial & 1 & 3 & 413 & $\begin{array}{l}\text { Aerodynamics } \\
\text { Combustion Efficiency }\end{array}$ & $\begin{array}{l}0.188 \\
0.164\end{array}$ & 0.200 \\
\hline Final & 1 & 3 & 310 & $\begin{array}{l}\text { Aerodynamics } \\
\text { Combustion Efficiency }\end{array}$ & $\begin{array}{l}0.143 \\
0.184\end{array}$ & 0.200 \\
\hline
\end{tabular}

\section{Table 3}

Primary zone dimensions

\begin{tabular}{llll}
\hline Iteration & Mass flow rate (swirler) $\mathrm{Kg} / \mathrm{s}$ & Mass flow rate (primary zone) $\mathrm{Kg} / \mathrm{s}$ & Length of primary zone $(\mathrm{mm})$ \\
\hline Initial & 0.43 & 0.43 & 108 \\
Final & 0.4805 & 0.4805 & 105 \\
\hline
\end{tabular}

Table 4

Secondary zone dimensions

\begin{tabular}{llllll}
\hline Iteration & $\mathrm{Y}_{\max } / \mathrm{d}_{\mathbf{j}}$ & $\begin{array}{l}\text { Diameter of jet }\left(\mathbf{d}_{\mathbf{j}}\right) \\
\mathrm{mm}\end{array}$ & $\begin{array}{l}\text { No.of } \\
\text { Holes }\end{array}$ & $\begin{array}{l}\text { Diameter of } \\
\text { holes }(\mathrm{mm})\end{array}$ & $\begin{array}{l}\text { Length of secondary } \\
\text { zone }(\mathrm{mm})\end{array}$ \\
\hline Initial & 5.78 & 7.69 & 24 & 10 & 356 \\
Final & 4.733 & $9.4 \mathrm{~mm}$ & 16 & 12.5 & 356 \\
\hline
\end{tabular}

Table 5

Dilution zone dimensions

\begin{tabular}{llllll}
\hline Iteration & $\mathrm{Y}_{\max } / \mathrm{d}_{\mathrm{j}}$ & Diameter of jet $\left(\mathbf{d}_{\mathbf{j}}\right) \mathrm{mm}$ & No. of holes & Diameter of holes $(\mathrm{mm})$ & Length of dilution zone $(\mathrm{mm})$ \\
\hline Initial & 4.055 & 14.632 & 6 & 18.5 & 267 \\
Final & 3.44 & 17.25 & 4 & 22 & 267 \\
\hline
\end{tabular}

Table 6

Overall dimensions

\begin{tabular}{lllll}
\hline Iteration & Primary zone $(\mathrm{m})$ & Secondary zone $(\mathrm{m})$ & Dilution zone $(\mathrm{m})$ & Total $(\mathrm{m})$ \\
\hline Initial & 0.108 & 0.356 & 0.267 & 0.731 \\
Final & 0.105 & 0.356 & 0.267 & 0.728 \\
\hline
\end{tabular}

\section{Instrumentation}

Instrumentation assumes vital significance in a test rig, as it allows us to record the key parameters of the fluid. The Placement of temperature and pressure probes has a direct relation with the compressor entry and exit points, therefore the diameter of these pipes has to be in line with those of inlet and outlet of the test component. Additionally, the standard stipulates that the measuring probes for certain flow devices to be placed only after a certain distance from the entry or exit and not immediately near them as shown in Figure 4. Pipe arrangements and allowable exceptions are described in this section. Pressure and temperature transducers with appropriate pressure ranges are identified for the current proposal and all the placements are governed by ASME 
PTC10 standard [10] which emphasizes on proper calibration and testing of instruments before being put to use. For the current test rig, four pressure probes are placed 90 degrees apart, and their average gives the static pressure. The instrumentation standard dictates that diameter of the static hole should not exceed four-tenths of the pipe wall thickness and the holes to be smooth and free of burrs. The standard however does not dictate the terms for Internal pressure measurements and leaves it to the user. However, as a rough guide, probes should be used at the preferred section(static or dynamic) in such a way that the incoming stream does not affect the measurement[5]. In discharge sections, as the flow has high velocity, there arises difficulty and uncertainty in its measurements and the same should be accounted for, during the calculation. Temperature should be measured by thermocouples or mercury-in-glass thermometers or other devices with equivalent accuracy. The decision on the range of the measuring device and its accuracy should be made on a case to case basis in line with the deviation levels as mentioned in the standard.

For temperature measuring devices, the thermal effect between the probe and external bodies be it by convection, conduction should be very minimal compared to that between the probe and the fluid. Welding or silver brazing of the thermocouple junction is preferred. Appropriate materials should be chosen for the application keeping in mind about the maximum temperature that can be reached. Assembly lever calibration should be done with the inclusion of thermo-well, lead wires and the instrument.

Static temperature and velocity temperature together yields total temperature of the fluid at any given point. For flows with Mach number less than 0.11 and for flows with velocity less than $38 \mathrm{~m} / \mathrm{s}$, the effect of velocity temperature becomes negligible and barring such cases, the measured temperature falls within static and total temperature. The velocity temperature component alone, is adjusted with a recovery factor and recorded. For temperature measurement at the inlet, four temperature probes are placed such that, they are at right angles to each other and staggered by 45 degrees to pressure probes in the inlet pipe as shown in Figure 4. In case of open inlet, the atmospheric temperature becomes the total temperature and the measuring probes are attached to a protective screen. The final measurement is the average of the values measured by the four probes and in case, if the measurements deviate by more than $0.5 \%$, the main reason for deviations should be identified and rectified. The same procedure is followed for compressor outlet. The instrumentation for both inlet and outlet is shown in Figure 5.

The vital parameters that are to be tracked are inlet outlet temperatures, pressures, flow rate and the rotational speed. The current rig uses pneumatic controlled diaphragm valves for adjusting the flow rate of air fuel and hot gases, while Kulite pressure sensors (10 Bar with an accuracy of $0.1 \%$ ) was identified as the best choice for pressure measurements as it was successfully implemented in couple of rigs around the world [4,5] for transient analysis. K-type thermocouple which can measure up to $1000^{\circ} \mathrm{C}$ with an accuracy of $\pm 2.8^{\circ} \mathrm{C}$ was identified as the suitable one for test section and combustor unit, and a J-type thermocouple (which can measure up to $375^{\circ} \mathrm{C}$, with $\pm 1.5^{\circ}$ accuracy) was identified as the best for cooling unit. It is to be noted that this research work also covers the placement of these measurements instead of merely stating the range and accuracy. The Figure 4 states the generic guide lines for the placement of Pressure and temperature sensors while Figure 5 ( $a$ and $b$ ) shows the application in reality.

\section{Testing Procedure}

The procedure for carrying out the performance test of the compressor is in accordance with ASME PTC 10 Standard [10] but confined to industry alone as early as 1960, Van Laningham [7] in his paper, has emphasized the use of standards in order to carry out testing of turbo components but it 
is hitherto being mentioned in detail about the placements (Figure 4 and 5) and the way how a rig has to be operated. A basic Rig Operating sequence was developed so that internal automation can be done based on this process flow as shown in Figure 6 . The main aim of testing is to analyse the following parameters in a centrifugal compressor
i. Quantity of gas delivered
ii. Pressure rise produced
iii. Establishment of Compressor Map
iv. Shaft power required
v. Efficiency
vi. Surge Point
vii. Choke Point

However, in order to calculate the above parameters, many input parameters and associated derived parameters are required. A typical compressor map will be generated as shown in the Figure 7. The test component will be operated from choke point to surge at various speeds and the abovementioned parameters will be calculated at each and every point.

The stability of key parameters is a must, before recording is done. For this, the compressor is allowed to run for sufficient time. Only after stability, all parameters are recorded, and the minimum duration for such recording is 15 minutes, as per standard. If the compressor is to be tested for a particular operating condition, the testing point should be as close to the given conditions as possible and should be within $\pm 4 \%$ of the preferred set point. However, if the entire performance mapping is to be done, then several points along each curve should be tested in the same way of single point testing. When stability is attained for a particular point, the input from DAQ is collected and the performance parameters are calculated usually by a commercial software. In cases where an inhouse facility is preferred, the data acquisition, calculation and continual operation of the rig should be automated with the help of MATLAB/LABVIEW codes. The basic sequence is of paramount importance for the automation and the same is provided in the Figure 6 along with the full layout of the test facility finally shown in Figure 8.

\section{Conclusion}

The present work provides a detailed documentation of the design of a gas stand from the beginning. This will help the OEM to test the integrated system of both prime mover and turbo charger for the various load conditions. this rig specifically targets Compressors and Turbo Chargers that find their use in Expendable Turbojets, Small Gas Turbines and UAV's (Unmanned Aerial Vehicles) which has both high mass flow as well as high RPM (in the order of $10^{5}$ RPM) usually for high RPM range turbochargers the mass flow rate is minimal (typically used in CARS AND HCV Trucks) and not many Test facility cater to this range of compressors and Turbochargers. This test rig also gives us the flexibility to test Mixed flow compressors apart from the conventional Radial compressors which is still in an emerging stage and further enhancements can be made to the existing rig to account for the mixed flow compressors and their flow behaviours. The automation of the test rig opens up further research scope as the present-day automation are mostly provided by Commercial establishments. A complete automation module can be built from the operational sequence provided here which will prove to be cost effective by providing the performance characteristics without user intervention. 


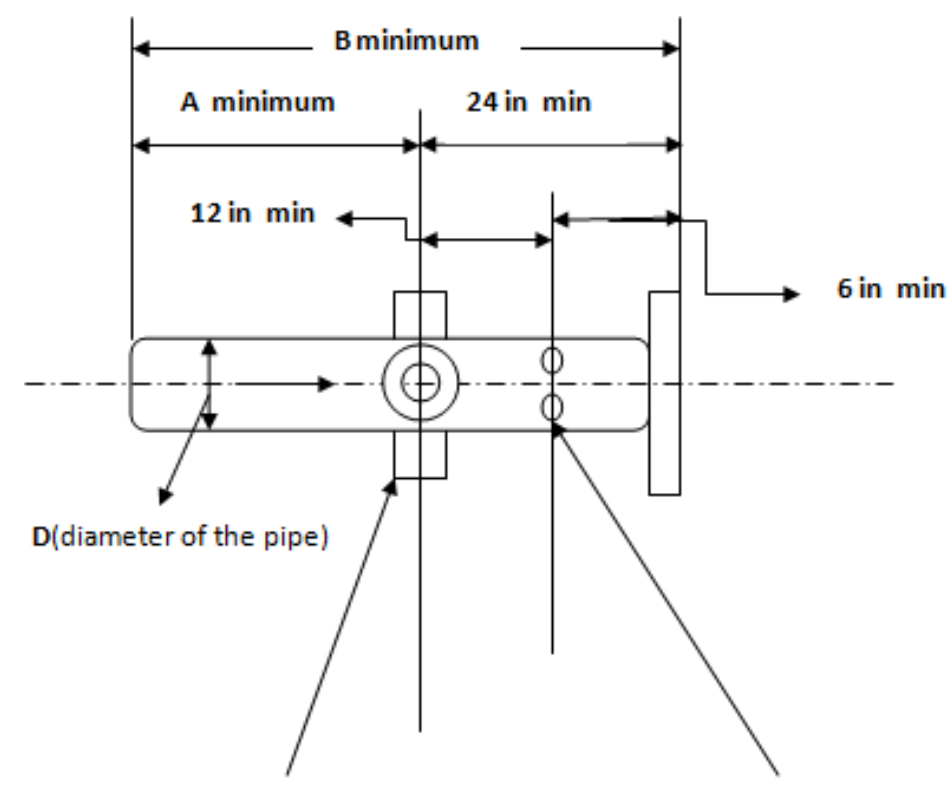

Inletstatic pressure

Inlet Static temperature

measurement station, 4

measurement station, 4

pressure taps placed 90

taps placed 90 degrees

degrees apart

apart and 45 degrees

staggered from the

pressure taps upstream.

\begin{tabular}{|c|c|c|}
\hline \multirow{2}{*}{ Inlet Opening Preceded by } & \multicolumn{2}{|c|}{ Minimum Dimensions } \\
\cline { 2 - 3 } & A & B \\
\hline Straight Run & 2D & 3D \\
\hline Elbow & 2D & 5D \\
\hline Reducer & 3D & 10D \\
\hline Valve & 8D & 5D \\
\hline Flow Device & 3D & \\
\hline
\end{tabular}

Fig. 4. Inlet instrumentation placement configuration 


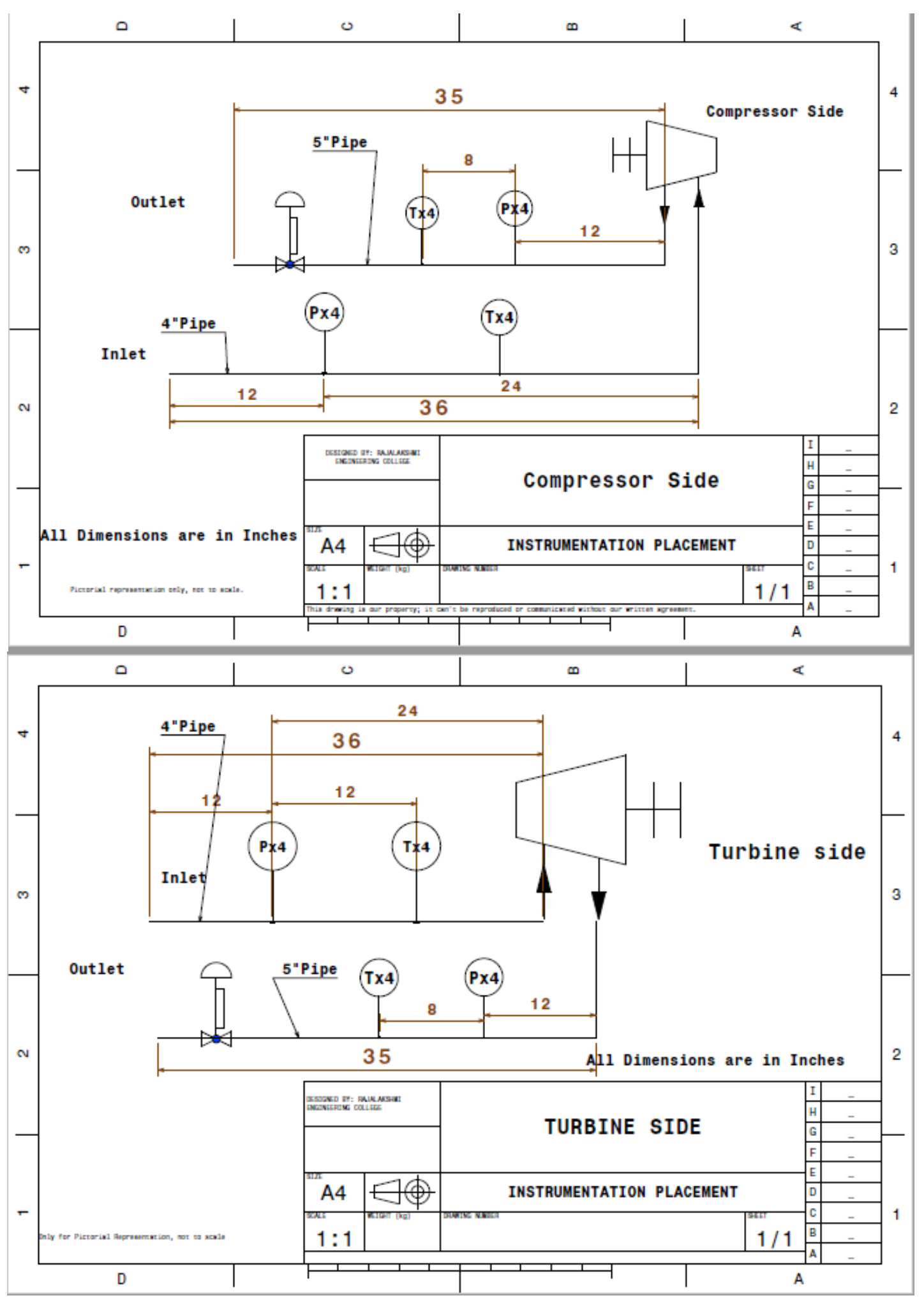

Fig. 5. Inlet - outlet instrumentation of the test section based on ASME PTC10[10] 

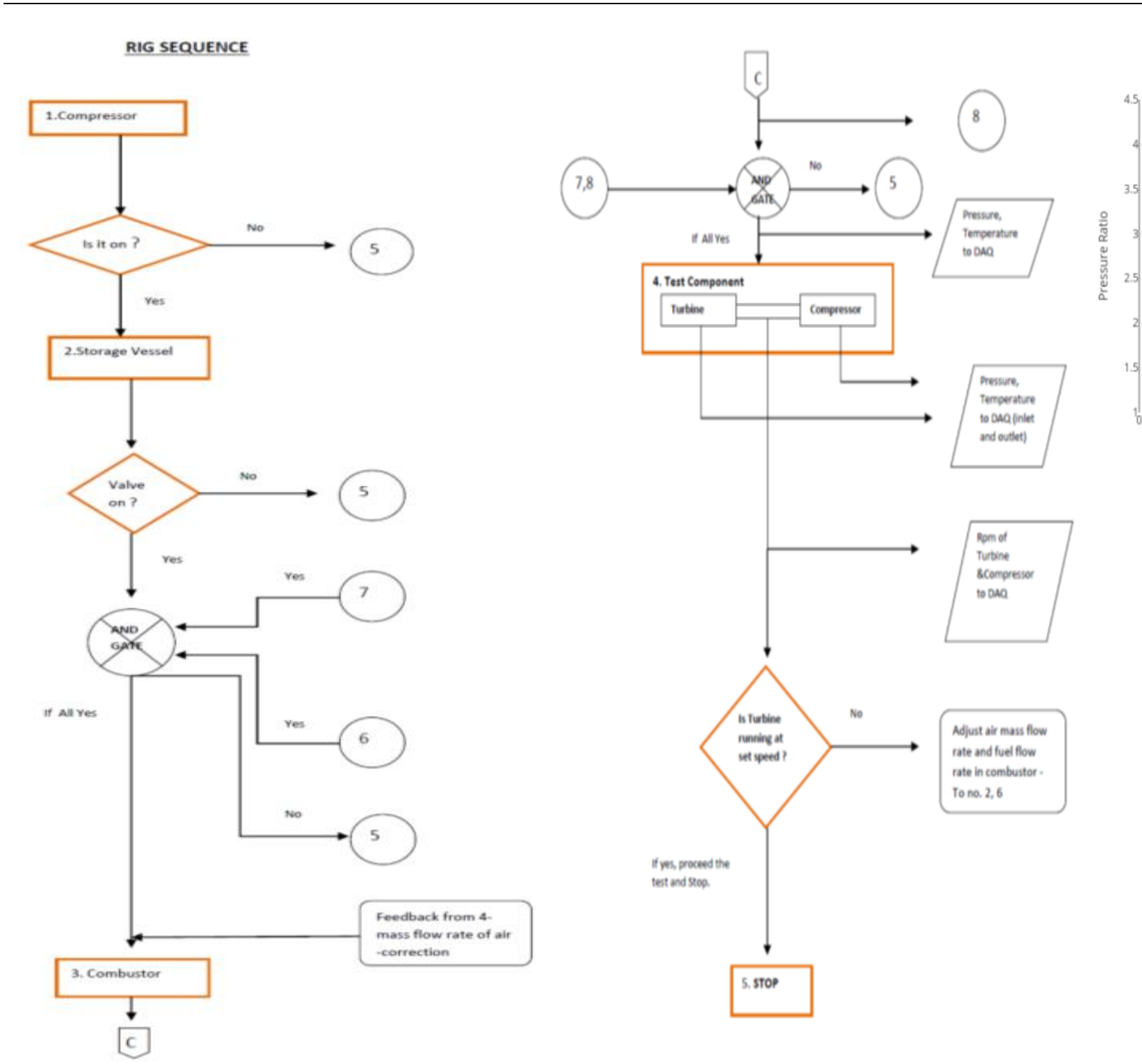

Compressor Map

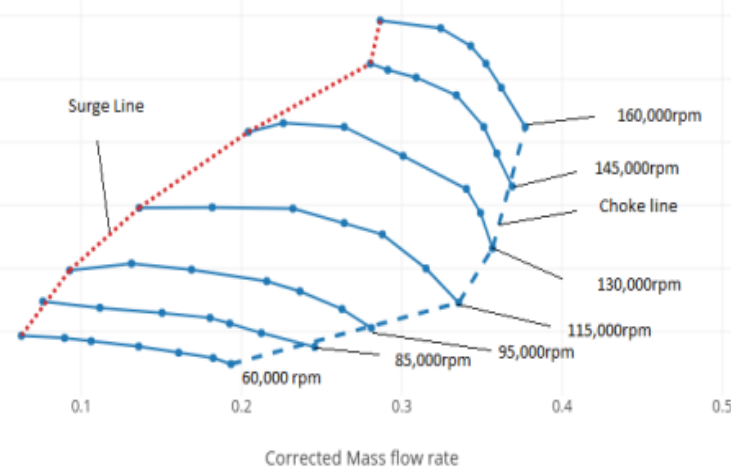

Fig. 7. Compressor map

Fig. 6. Test rig operating sequence 


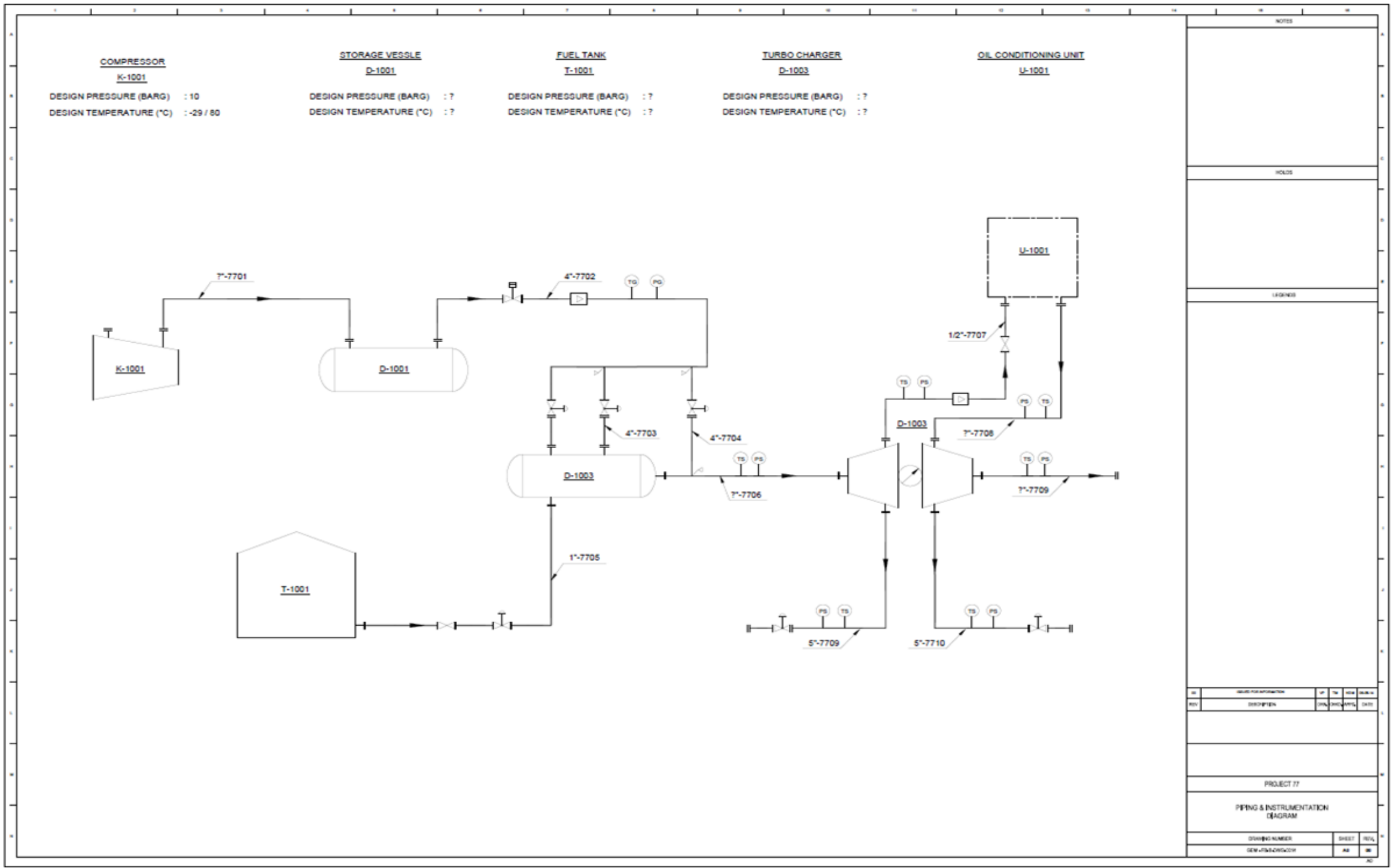

Fig. 8. Overall layout of the test rig 


\section{Acknowledgement}

The authors would like to acknowledge GTRE-GATET program cell for their funding and technical support. The Authors declare that there is no conflict of interest.

\section{References}

[1] Al-Sulaiman, Fahad A., and Amro M. Al-Qutub. "Design of Small Centrifugal Compressors Performance Test Facility." In Turbo Expo: Power for Land, Sea, and Air, vol. 41707, pp. 227-235. 2004.

https://doi.org/10.1115/GT2004-53821

[2] Chernov, Mikhail. "Design of a test stand for a centrifugal compressor." Master thesis, Lappeenranta University of Technology (2013).

[3] Mosdzien, M., M. Enneking, A. Hehn, D. Grates, and P. Jeschke. "Influence of blade geometry on secondary flow development in a transonic centrifugal compressor." Journal of the Global Power and Propulsion Society 2, no. 1 (2018): 429-441.

https://doi.org/10.22261/JGPPS.I1RSJ3

[4] Meuleman, Corina Henrica Jacoba. "Measurement and unsteady flow modelling of centrifugal compressor surge." (2002).

[5] Lim, Kin Tien, Se Young Yoon, Christopher P. Goyne, Zongli Lin, and Paul E. Allaire. "Design and characterization of a centrifugal compressor surge test rig." International Journal of Rotating Machinery 2011 (2012): 5-9. https://doi.org/10.1155/2011/738275

[6] Bontempo, Rodolfo, Massimo Cardone, Marcello Manna, and Giovanni Vorraro. "Highly flexible hot gas generation system for turbocharger testing." Energy Procedia 45 (2014): 1116-1125.

https://doi.org/10.1016/i.egypro.2014.01.117

[7] Van Laningham, Fred L. "Guidelines For Performance Testing Centrifugal Compressor." In Proceedings of the 10th Turbomachinery Symposium. Texas A\&M University. Turbomachinery Laboratories, 1981.

[8] Turner, A. B., S. J. Davies, P. R. N. Childs, C. G. Harvey, and J. A. Millward. "Development of a novel gas turbine driven centrifugal compressor." Proceedings of the Institution of Mechanical Engineers, Part A: Journal of Power and Energy 214, no. 5 (2000): 423-437.

https://doi.org/10.1243/0957650001537985

[9] Smith, Clayton T., George Beltz, and Dennis K. Williams. "ASME applicability for small modular reactors." In International Conference on Nuclear Engineering, vol. 44984, pp. 189-194. American Society of Mechanical Engineers, 2012.

[10] PTC, ASME. "10, 1997, "Performance Test Code on Compressors and Exhausters,"." American Society of Mechanical Engineers, New York, New York (1997).

[11] Koupper, Charlie, Gianluca Caciolli, Laurent Gicquel, Florent Duchaine, Guillaume Bonneau, Lorenzo Tarchi, and Bruno Facchini. "Development of an engine representative combustor simulator dedicated to hot streak generation." Journal of Turbomachinery 136, no. 11 (2014). https://doi.org/10.1115/1.4028175

[12] Hatch, M. S., W. A. Sowa, G. S. Samulersen, and J. D. Holdeman. "Geometry and flow influences on jet mixing in a cylindrical duct." Journal of Propulsion and Power 11, no. 3 (1995): 393-402. https://doi.org/10.2514/3.23857

[13] McLeroy, Jacob T., Duane A. Smith, and Mohan K. Razdan. "Development and Engine Testing of a Dry Low Emissions Combustor for Allison 501-K Industrial Gas Turbine Engines." In Turbo Expo: Power for Land, Sea, and Air, vol. 78804, p. V003T06A058. American Society of Mechanical Engineers, 1995. https://doi.org/10.1115/95-GT-335

[14] Carrotte, J. F., and S. J. Stevens. "The influence of dilution hole geometry on jet mixing." (1990): 73-79. https://doi.org/10.1115/1.2906480

[15] Talpallikar, M. V., C. E. Smith, M. C. Lai, and J. D. Holdeman. "CFD analysis of jet mixing in low NOx flametube combustors." (1992): 416-424.

https://doi.org/10.1115/1.2906607

[16] Povey, T., K. S. Chana, T. V. Jones, and J. Hurrion. "The effect of hot-streaks on hp vane surface and endwall heat transfer: An experimental and numerical study." (2007): 32-43.

https://doi.org/10.1115/1.2370748

[17] Simone, Salvadori, Francesco Montomoli, Francesco Martelli, Kam S. Chana, Imran Qureshi, and Tom Povey. "Analysis on the effect of a nonuniform inlet profile on heat transfer and fluid flow in turbine stages." Journal of Turbomachinery 134, no. 1 (2012).

https://doi.org/10.1115/1.4003233 
[18] Shang, T., G. Guenette, A. Epstein, and A. Saxer. "The influence of inlet temperature distortion on rotor heat transfer in a transonic turbine." In 31st Joint Propulsion Conference and Exhibit, p. 3042. 1995. https://doi.org/10.2514/6.1995-3042

[19] Shih, Tsan-Hsing, William W. Liou, Aamir Shabbir, Zhigang Yang, and Jiang Zhu. "A new k- $\epsilon$ eddy viscosity model for high reynolds number turbulent flows." Computers \& fluids 24, no. 3 (1995): 227-238. https://doi.org/10.1016/0045-7930(94)00032-T

[20] Schonfeld, Thilo, and Michael Rudgyard. "Steady and unsteady flow simulations using the hybrid flow solver AVBP." AIAA journal 37, no. 11 (1999): 1378-1385. https://doi.org/10.2514/2.636

[21] Lefebvre, Arthur H., and Dilip R. Ballal. "Gas Turbine Combustion: Alternative Fuels and Emissions." Crc Press, 2010. https://doi.org/10.1201/9781420086058

[22] Coleman, Hugh W., and W. Glenn Steele. "Engineering application of experimental uncertainty analysis." $A I A A$ journal 33, no. 10 (1995): 1888-1896. https://doi.org/10.2514/3.12742

[23] Mattingly, Jack D., William H. Heiser, and David T. Pratt. Aircraft engine design. American Institute of Aeronautics and Astronautics, 2002. https://doi.org/10.2514/4.861444

[24] Agarwal, Varija, And Donna Post Guillen. "Multiphysics Integrated Coupling Environment (Mice) User Manual. No. Inl/Ext-13-29799." Idaho National Laboratory (INL), 2013. https://doi.org/10.2172/1097184 